\title{
Future Technology Workshop: A Collaborative Method for the Design of New Learning Technologies and Activities
}

\author{
Giasemi N. Vavoula ${ }^{1}$ and Mike Sharples ${ }^{2}$ \\ ${ }^{1}$ Department of Museum Studies, University of Leicester, UK, gv18@le.ac.uk \\ ${ }^{2}$ Learning Sciences Research Institute, University of Nottingham, UK, mike.sharples@nottingham.ac.uk
}

\begin{abstract}
We describe the Future Technology Workshop (FTW), a method whereby people with everyday knowledge or experience in a specific area of the use of technology (such as the use of digital cameras) envision and design the interactions between current and future technology and activity. Through a series of structured workshop sessions they collaborate to envisage future activities related to technology design, build models of the contexts of use for future technologies, act out scenarios of use for their models, re-conceive their scenarios in relation to present-day technologies, list problems with implementing the scenarios, explore the gap between current and future technology and activity, and end by listing requirements for future technology. The method has been used successfully with children and adults to explore new technology-activity systems including interacting with digital photographs and informal science learning.
\end{abstract}

\section{Introduction}

Since the early 1980s (Sharples, 1987), through a series of major projects with industry and academic partners, we have developed and refined a method, named socio-cognitive engineering, for human-centred design of socio-technical systems (Sharples, Jeffery, du Boulay, Teather, Teather, \& du Boulay, 2002; Sharples, 2006). Like participatory design and related approaches, socio-cognitive engineering draws on the knowledge of potential users and involves them in the design process. It extends beyond individual users to analyze the activity systems of people and their collaborative interaction with technology, including their social interactions, styles and strategies of working, language and patterns of communication, to produce a composite picture of human knowledge and collaborative activity that informs systems design and implementation. The socio-cognitive engineering framework consists of two main parts: a phase of activity analysis to interpret how people work and interact with their current tools and technologies, and a phase of systems development to design, build and implement new interactive technology. Through this structured process of analysis and development, based on the relation between a Task Model that synthesizes the activity analysis, and a Design Concept that guides software engineering, socio-cognitive engineering has provided a shared method for multi-disciplinary teams to develop large systems for knowledge work and collaborative learning such as the MOBIlearn European mobile learning platform (Bo, 2005).

From the experience of projects such as MOBIlearn and MEDIATE (Sharples et al., 2002) we also discovered limitations of the approach. One significant problem is that design methods grounded in an analysis of everyday activity are not appropriate for developing radically new or disruptive devices that overturn current technologies (Bower \& Christensen, 1995). Nor are they suited to envisioning how people might learn, work or play together in a future of 
pervasive computing. It would be tempting simply to bolt a 'future gazing' method, such as a Delphi survey (Delbecq, Ven, \& Gustafson, 1975) or scenario planning (Schwartz, 1997), onto the front of socio-cognitive engineering, but these are designed to support group decision making or assist strategy planning, not to inform systems design. Thus, we identified a need for a method that can directly inform a process of human-centred systems design. To fit into that process it needs to meet the following criteria:

a) Minimal participant training. It can be used with adults or children with no prior training in software design to enact and analyse collaborative interaction with technologies that have not yet been envisaged.

b) Collaborative. It can involve group activities to role play the interactions between people and future collaborative technology, to support the design of CSCW and CSCL systems.

c) Direct input to design. It forms part of a human-centred approach to software engineering, producing general requirements that can guide programmers and technology designers.

d) Cost-effective to run. It can be carried out in any large room, with cheap and portable equipment, in a day workshop.

e) Relates people and technology. It explores the relations between future activity and future technology, providing requirements for socio-technical systems, not just new pieces of hardware.

f) Open-ended. It does not constrain the form and scope of the new socio-technical system by requiring (or excluding) certain patterns of behaviour or certain use contexts.

g) Pragmatic. It identifies those activities that meet a human need and also could conceivably be designed by practical present-day engineering methods.

The following section surveys current methods for participatory design and assesses them against these criteria.

\section{Existing methods}

Many participatory design methods have been developed to involve users in the technology design lifecycle, including informant design (Scaife \& Rogers, 1999), contextual inquiry (Beyer \& Holtzblatt, 1998), technology immersion (Druin, Bederson, Boltman, Miura, Knotts-Callahan, \& Platt, 1999), and low-tech prototyping (Ehn \& Kyng, 1991). Muller and Kuhn (1993) classified Participatory Design techniques according to when in the design process the technique is applied (early, as in Future Workshops, or late, as in participatory analysis of usability data) and whether the technique involves designers participating in the users' world (e.g., ethnography), or users participating in the designers' world (e.g., PICTIVE - Muller, 1991).

This paper covers only those methods that are intended for the exploratory parts of design, to envisage future technologies or technology-enabled societies, such as Future Workshops (Kensing \& Halskov-Madsen, 1991) and Strategic Visioning Workshops (Sanders, 2000). Similar techniques that are intended to provoke innovation in the design of products and services have been developed outside Participatory Design, such as the Lead User method (von Hippel, 1986), adapted focus groups, reported in Industrial Design projects (Bruseberg \& McDonagh-Philp, 2001), and the Focus Troupe (Salvador \& Sato, 1998). The following subsections analyse methods within and around Participatory Design, with reference to the 
criteria listed in the Introduction. The discussion focuses only on those methods that are specifically intended to envisage future technologies and interactions that reach beyond traditional settings (such as the workplace or the classroom) and into everyday life more generally, thus leaving out some of the classic Participatory Design methods that are concerned with the analysis of traditional work and learning settings (see for example Scaife \& Rogers, 1999; Beyer \& Holtzblatt, 1998; Druin et al., 1999; Muller, 1991).

\section{Focus groups to bridge Ergonomics and Industrial Design}

Bruseberg and McDonagh-Philp (2001) document approaches from Industrial Design for applying focus group techniques to elicit user needs, aspirations and emotions for the development of successful new products. Applied in the context of small domestic kitchen appliances, the approach interprets the term 'focus group' broadly and uses it as a generic term "in favour of other terms such as workshop or participatory discussion" (Bruseberg and McDonagh-Philp op. cit., p. 439). It explores the combination of focus groups with other techniques such as presentations, mood boards, product personality profiling, and sketching.

The approach appears to be cost-effective and pragmatic. The outcomes of the focus group were analysed in two stages. First, the design researcher produced tables summarising concepts and their frequency of mention in the focus groups as well as rankings of purchase priorities, lists of ideas and comments. Then, further brainstorming among the design team "provided further insight into the results, clarified questions and specified product requirements” (Bruseberg \& McDonagh-Philp, op. cit., p. 448). Thus, although the method clearly provides input for the design process, this input comes from the designers' interpretations of the focus group sessions, not directly from the participants. The main limitation is that participants in focus groups talk about the design of new technology, rather than engaging in the design as participants in the process of modelling artefacts and role playing the activities involved in interacting with them.

\section{Future Workshops and other Co-operative Design Workshop formats}

Jungk and Müllert (1987) developed Future Workshops as a technique to enable citizen groups with limited resources to have a say in the decision making processes of public planning authorities. Kensing (1987) proposed its use in system development, as a means to envision how IT can support future work situations. A Future Workshop includes three phases: the Critique phase (a structured brainstorming session that focuses on existing problems related to the design task), the Fantasy phase (the participants envision a future free of the previously identified problems), and an Implementation phase (a group discussion on the feasibility of the vision that resulted in the Fantasy phase and the development of an action plan for the implementation of the vision). Kensing and Halskov Mansen (1991) further suggested the integration of Future Workshops with metaphorical design, where metaphors are introduced at critical points by the facilitators to broaden the perspectives of the participants.

Arvidsson, Ihlström, and Lundberg (2002) suggest complementing the Fantasy phase of the Future Workshop with a Trigger phase, where possible technological solutions are demonstrated to aid the participants to imagine what might be possible. Ihlström, Svensson, and Åkesson (2005) have used a combination of an adaptation of Future Workshops with 
scenario building, mock-up construction and focus groups for the design of future everyday IT artefacts (namely, the e-Newspaper of the future).

Svanaes and Seland (2004) present another structure for cooperative design workshops for design projects involving mobility and computer-mediated communication. Their proposed workshop structure starts with a drama and scenario building session, where participants engage in scenario creation and role-play after being introduced to drama techniques and presented with the goals of the workshop (optionally with the aid of presentations of data from the field). This is followed by mock-up design, using Post-it@ notes and foam models.

These workshop formats appear to meet the criteria for minimal participant training (with the exception perhaps of the drama workshops, which require training participants in drama techniques), collaborative group activities, cost-effectiveness (again, with the exception of drama workshops which require a professional drama facilitator), pragmatism and focus on people as well as technology. However, they do not meet the criteria for open-endedness and direct input to design.

In particular, they seem to start with the presentation of solution ideas (e.g., e-Ink technology), technology triggers (e.g., video clips of future use and pictures of prototypes), data from the field, or identified problems in participants' own current practices. Priming the participants so early in the workshop with data from existing practices and issues may have a negative impact on the advance of the workshop: "how the idea of the artefact is presented and which triggers and materials for mock-ups are chosen, all influence participant input very much. Therefore, it is very important that these decisions are carefully considered" (Ihlström et al. 2005, p. 18). Grounding the workshop from the onset in experiences and problems of the present day and priming the participants with suggestions for new technology may restrict the ideas and requirements to the technological limitations of the present, which may soon become obsolete anyway. Considering possible technological solutions before exploring what the problem might be like in the future (i.e., by looking at technology first and then thinking about activity around that technology), can constrain creativity and breakthrough thinking. As Inkpen (1999) reports from experiences of designing future handheld technologies for children: "while this activity was successful in identifying important issues for the design of handheld computers, many of the children were constrained by their preconceived notions about what constitutes a computer and the functionality it can provide”. (Inkpen op. cit., p. 86).

Furthermore, none of the abovementioned workshop structures elicits requirements from the participants directly: it is up to the design team to interpret the process and outcomes of the workshop in order to draw out user requirements rather than to obtain requirements that are promptly available along with the rationale behind them.

\section{Generative Tools and Strategic Visioning Workshops}

Sanders (2000) describes the use of tools to give people the opportunity to express their dreams of an ideal, future world visually and verbally in a way that can inform and inspire the design development process. What he calls 'generative tools' includes tools designed to elicit emotional responses and expressions from people, as well as tools to uncover meaning and cognitive understanding. These are contained in a 'toolkit', which "usually contains a background on which to work, together with a large number of simple and ambiguous 
components that can be arranged and juxtaposed in a variety of ways” (Sanders op. cit., p. 7). The visual components include photographs, sketches, coloured paper cut into shapes, and three-dimensional forms covered with Velcro material. These can be annotated with pens, crayons or markers.

Strategic Visioning Workshops employ the toolkits to facilitate effective collaboration: "the transformation that takes place when a group of people goes from a verbal exchange of ideas to a collective and visually expressive mode is remarkable. It is invariably positive and can often be quite therapeutic for the participants.” (Sanders op. cit., p. 11).

The generative tools appear to be simple, low-cost and easy to use, and participants need minimal instructions to start working with the tools. In the Strategic Visioning Workshop format, they also facilitate collaboration effectively. The focus of the process is on people, their dreams and aspirations, and technology does not get in the way. Participants are free to use the tools as they wish and produce anything they like. However, Strategic Visioning Workshops as described in Sanders (op cit.) do not meet the criteria for providing direct input to design: the outcomes of using the generative tools are visual displays such as collages, which may be a rich source of data for a design team, but do not provide an explicit set of requirements. Moreover, the workshops are not necessarily pragmatic: participants are free to express their 'dreams' and no attempt is made to ground those dreams in today's world.

\section{Role playing games and SPES (Situated and Participative Enactment of Scenarios)}

Iacucci, Kuutti, and Ranta (2000) suggest the use of role-playing games and situated and participative enactment of scenarios (SPES) as methods that overcome three design challenges: open-ended design, designing for mobility, and designing beyond the workplace. Role-playing games require that designers set up games to simulate contexts and events while participants role-play within the context of the game to envision services and technologies appropriate for the situations formed. SPES involves the designer 'shadowing' a user for one to two days, with the user carrying a mock-up device which they use to enact scenarios created on the fly, based on real-life situations that either the designer or the user considers interesting.

Both techniques are low cost, pragmatic, and do not appear to require any participant training. Role-playing games are collaborative, whereas SPES involves a single user at a time. The main outcome of both techniques is scenarios that showcase uses of new products and services. These scenarios need to be further analysed by the design team to deduce requirements. Moreover, although the techniques are meant to support open-ended design, the degree of openness allowed is limited: the role-playing games are "flexible enough to allow a co-development of services and devices” (Iacucci, Kuutti, \& Ranta , op.cit., p.199), however these are based around familiar use contexts and activities; SPES results in realistic scenarios extracted from the participant's everyday practice, but again offers no flexibility to envision changes in everyday practice. Therefore, although the two techniques are independent of specific work tasks, they are still based on current activities and practices.

\section{The Lead User method and Lead Users Workshop}

Von Hippel (1986) suggested the involvement of 'Lead Users' in the development of new product concepts. Lead users are those users of existing products who currently face needs 
that will eventually become general in the marketplace and also expect to benefit significantly from a solution to those needs. Meeting these two criteria makes Lead Users good candidates for drawing the attention of designers and developers to potentially important needs that existing solutions do not satisfy, and for suggesting preliminary solutions by reflecting on how they presently overcome these problems. Herstatt and von Hippel (1992) conducted a new product design workshop with Lead Users in the context of manufacturing pipe hangers. The workshop took place over three days, and included the Lead Users identifying trends and problems, specifying problem areas, and finding solutions to these problems as suggested designs. Herstatt and von Hippel (op. cit.) report that the outcomes of the Lead User Workshop were designs which were valued by the manufacturer and led to successful products. The whole process, from specification of Lead User criteria to design recommendations, took nine months to complete. Although the participants do not need special training to participate, the process of identifying Lead Users involves several steps and is not straightforward. The participants work together in small groups on the solutions they come up with, with each participant required to rotate through all sub-groups to avoid bias. The outcome of the workshop is directly usable in design and pragmatic, as it is in essence a first specification of an immediately implementable solution that stems from the experiences and practical problems faced by the participants. However, the whole workshop is highly focused on a specific piece of technology. Although it is successful in the design of new replacement products, it may not be suitable for the design of radically new or disruptive socio-technical systems, for which Lead Users do not yet exist.

Table \#1 compares the methods and techniques discussed above against the criteria we set out in the Introduction. As it shows, none of the reviewed techniques satisfies all the criteria. Two methods (Future Workshops and Strategic Visioning Workshops) satisfy five of the seven criteria, but neither were developed to provide direct input to a process of human-centred systems design.

Table \#1. Comparison of existing methods and techniques against criteria for method for the design of disruptive socio-technical systems.

\begin{tabular}{|l|c|c|c|c|c|c|c|}
\hline Method & $\begin{array}{l}\text { Minimal } \\
\text { participan } \\
\text { t training }\end{array}$ & $\begin{array}{l}\text { Collabo- } \\
\text { rative }\end{array}$ & $\begin{array}{l}\text { Direct } \\
\text { input to } \\
\text { design }\end{array}$ & $\begin{array}{l}\text { Cost- } \\
\text { effective } \\
\text { to run }\end{array}$ & $\begin{array}{l}\text { Relates } \\
\text { people with } \\
\text { technology }\end{array}$ & $\begin{array}{l}\text { Open- } \\
\text { ended }\end{array}$ & Pragmatic \\
\hline $\begin{array}{l}\text { Focus } \\
\text { groups }\end{array}$ & $\checkmark$ & X & X & $\checkmark$ & X & X & $\checkmark$ \\
\hline $\begin{array}{l}\text { Future } \\
\text { Worskhops }\end{array}$ & $\checkmark$ & $\checkmark$ & X & $\checkmark$ & $\checkmark$ & X & $\checkmark$ \\
\hline $\begin{array}{l}\text { Strategic } \\
\text { Visioning } \\
\text { Workshops }\end{array}$ & $\checkmark$ & $\checkmark$ & X & $\checkmark$ & $\checkmark$ & $\checkmark$ & X \\
\hline $\begin{array}{l}\text { Role-play } \\
\text { games }\end{array}$ & $\checkmark$ & $\checkmark$ & X & $\checkmark$ & X & X & $\checkmark$ \\
\hline SPES & $\checkmark$ & X & X & $\checkmark$ & X & X & $\checkmark$ \\
\hline $\begin{array}{l}\text { Lead User } \\
\text { Workshops }\end{array}$ & $\checkmark$ & $\checkmark$ & $\checkmark$ & $X$ & X & X & $\checkmark$ \\
\hline
\end{tabular}




\section{The future technology workshop method}

The Future Technology Workshop (FTW) was developed to meet the need for a methodical way of developing radically new or disruptive technology through envisioning how people might learn, work or play collaboratively in a future of pervasive computing. This need arose in two projects - Children as Photographers (www.cap.ac.uk) and MOBIlearn (www.mobilearn.org) - where the objectives were to explore how people in the future may interact with personal technologies and to inform the design of new technologies and their uses. For the Children as Photographers project, the aim was to understand how children might capture and share images in the future (the first session was held in 2001 when digital cameras were first becoming available to the mass market, and camera phones had not been introduced in Europe). For MOBIlearn, the aim was to develop and explore scenarios of use for a large European mobile CSCL project.

In the FTW method, participants who are familiar with the domain of interest (but are not generally technology experts) are guided through a process of exploring and designing the interactions between current and future technology, and current and future activities. These interactions form a grid, as shown in Table \#2. The FTW sessions address four questions: How are current activities performed with the support of current technologies (Box 1 in Table \#2)? How might these same activities be performed with new technologies in the future (Box 2 in Table \#2)? What new activities might current technologies support (Box 3 in Table \#2)? What new activities could be enabled by future technologies (Box 4 in Table \#2)?

Each of these interactions is valuable to systems designers. Box 1 in Table \#2 explores how people currently engage with technology (the starting point for the socio-cognitive engineering process and many other Participatory Design methods). Box 2 in Table \#2 extrapolates these activities to new technology, to understand whether the envisaged technology is familiar or disruptive. Box 3 in Table \#2 encourages the participants to explore new ways to engage with current technology. Box 4 in Table \#2 offers an opportunity for 'imagineering,'. The aim of a Future Technology Workshop is to reach an informed understanding of how people might interact with technology in the future (box 4 in Table \#2) by exploring the possibilities represented by all four boxes.

Table \#2. Interactions between activities and technology, now and in the future.

\begin{tabular}{|l|l|l|}
\hline & \multicolumn{1}{|c|}{ CURRENT TECHNOLOGY } & \multicolumn{1}{|c|}{ FUTURE TECHNOLOGY } \\
\hline CURRENT ACTIVITY & $\begin{array}{l}\text { 1. Everyday technology-mediated } \\
\text { activity }\end{array}$ & $\begin{array}{l}\text { 2. Familiar activities supported by } \\
\text { new technology }\end{array}$ \\
\hline FUTURE ACTIVITY & $\begin{array}{l}\text { 3. New activities that current } \\
\text { technology might support }\end{array}$ & $\begin{array}{l}\text { 4. New activities with new } \\
\text { technologies }\end{array}$ \\
\hline
\end{tabular}

This is achieved through a series of seven sessions, with a minimum of six and maximum 20 participants $^{2}$, plus two or three facilitators. The sessions are called: 1) Imagineering, 2) Modelling, 3) Role-play, 4) Retrofit, 5) Everyday, 6) Futurefit, and 7) Requirements. Each session has a defined outcome, which is recorded by the facilitators who manage the session. The workshop is typically carried out as a half-day event, with approximately two hours dedicated to the first four sessions, a one-hour break, and approximately 90 minutes for the remaining three sessions. An FTW toolkit is available for download, detailing the structure of 
the workshop, the materials necessary for each session, and instructions for carrying out each session (www.ftw.org.uk).

The workshop structure was finalised through a series of pilot studies held during 2001-2 (Vavoula, Sharples, \& Rudman, 2002). An important issue has been in which of the four boxes in Table \#2 to start the process, and where in the future (far or near) to focus. If it starts with current technology or activity, or the focus remains on the near future throughout, then the process risks just extrapolating from the present and missing the opportunities for designing radically new and disruptive technology - and activity. If it starts in the future, or the focus remains on the far future, it could result in fanciful activities and unworkable technology.

The initial research took place at a children's holiday camp in February 2001. At that point, only the imagineering and modelling sessions were carried out. Six boys and six girls, aged 11 years, participated. Although they generated ideas for new technologies, they did not propose how these might enable new everyday activities. The combination of technology and activity appeared to be necessary in order to refine the design ideas and to provide the children with the context necessary for identifying further technological requirements. As a result, the method was extended with additional sessions to role play with the models and to relate the models to existing technology.

A second pilot was carried out with six adults, comprising three engineers and three nonengineers, all students or staff of the University of Birmingham. Their design task related to ways of "capturing and sharing visual events and experiences in the future". Among the list of ideas they produced, was immersing people into the sights, sounds and feelings of another place and/or time. The additional workshop tasks did indeed help the participants to put the imaginary technologies in context. For example, a pair that had designed a robot to 'capture distant experiences' acted out how it might visit the owner's home town, interact with their friends and family, and transmit the experience back to the owner.

The pilot study raised a problem with the initial brainstorming session. Initially, the participants generated somewhat mundane suggestions that extended existing technology ('A record/diary of one's life in images'; 'A permanent record of everything one sees over a lifetime, that they can review at the end'). Only when the participants were asked to "think 'space age'” did the suggestions become more radical, for example: 'intelligent mechanism that records everything but recalls only what is important' and 'teleporting into a "photographic” reality, which also provides stimuli for other senses'.

A third pilot was designed to build on the outcomes of the second. The design task related to ways of "immersing into the sights and sounds of another place and/or time". It was carried out with seven adults, three engineers and four non-engineers, and all the sessions were completed. Several ideas for "immersive" activities were produced during imagineering. The third pilot resulted in alternative designs and ideas, but these were no more detailed than those produced in the second pilot. Furthermore, the second and third pilots produced a list of very general, non-functional requirements rather than more detailed, functional requirements that would be needed for further development of the ideas. Modifications to the FTW method were made so that the participants would be asked to list requirements specifically related to the models they produce, and also so that a follow-up workshop would build on a specific model from the first workshop rather than on abstract models. 
As a result of the pilot studies, we found that the most successful approach is to start with technology and activity in the far future (Box 4 in Table \#2). This frees the participants from the limitations of the present and engages them in an enjoyable future-gazing session. Then they follow a series of sessions to ground their ideas by exploring how they relate to current activity and technology and projecting these into the near future where new but achievable technologies emerge. Bruseberg and McDonagh-Philp (2001) describe the aim of new designs as being "to come reasonably close to the ideal, whilst not leaving the perception of the stereotype (standard) too far behind” (p 438). The FTW process facilitates the conceptualisation of the ideal followed by its re-conceptualisation through critical analysis of the stereotype, to arrive at new designs.

The method starts by presenting the participants with a topic to be explored, either because it presents opportunities for new interaction with technology (e.g., 'how would people capture, use and share images in the future?') or is an area of research interest (e.g., 'informal science learning'). Starting with Box 4 in Table \#2, it circles through 3, 1 and 2 and back to 4, travelling at the same time from the far future, to the present and recent past, and then to the near future. More specifically, the process starts in Box 4 in Table \#2, examining new activity and technology in the far future. The same activity of the far future is then brought into the present in Box 3 in Table \#2, to examine its feasibility with current technology. Current activities are then explored in Box 1 in Table \#2, with reference to recent past experiences, to identify limitations and problems in activities and technologies of the present day. The visions of Box 4 in Table \#2 as well as the realities and constraints of Boxes 3 and 1 are then merged into Box 2 in the near future, to examine whether and how emerging technology can support current activity. Finally, Box 4 in Table \#2 is revisited but this time it is placed in the near rather than the far future, ultimately to identify requirements for emerging technology to support emerging activities. Figure \#1 shows the sequence and placement in time of the different sessions of the FTW as they correspond to the four boxes in Table \#2. In the following sections we shall describe each session in detail.

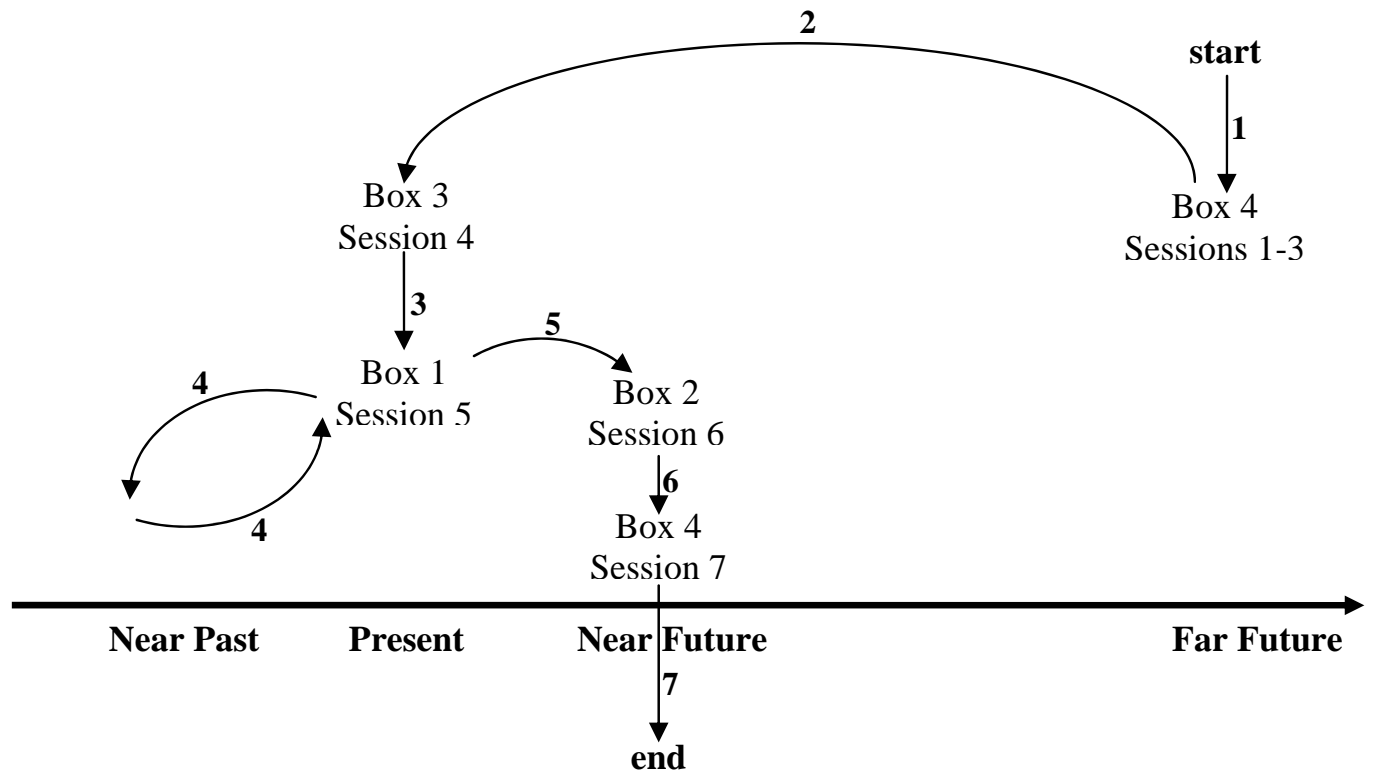

Figure \#1. Flow diagram of Future Technology Workshop sessions. 


\section{Session 1 - Imagineering}

At a glance: Participants envision future activities in relation to the design task Duration: 10-15 minutes (time required to produce an adequately rich and diverse set of ideas for future activities, depending on group size)

Techniques: Brainstorming

Number of Researchers: 1 - acting as a moderator for the brainstorming session

Purpose: To set the scene and get the participants to think in terms of the future, with respect both to the technology and to the needs satisfied by it.

Outcomes: A list of new activities that people would like to be able to perform in the future. A side effect of this session is also that the participants' outlook is now set to think of the future.

Table 2 grid box: 4 - Future activity

Placement in time: Far future

During the Imagineering session, the whole group of participants takes part in a brainstorming exercise to envisage future activities in relation to the design task at hand. Brainstorming is a method for creative idea generation from a group of people (Osborne 1963), that comprises a facilitator and the idea-generating participants. The basic rules for successful brainstorming include the following: (a) avoid judgement during the idea generation, (b) quantity breeds quality, (c) verbalise ideas as soon and as often as they occur, and (d) combine ideas and build on each other's ideas (Jonassen, Tessmer, \& Hannum, 1999, p. 264). The generated ideas are noted by the facilitator and put on public display, e.g., on a flip chart. The facilitator may cluster the ideas as they are produced with the aid of the participants. Often clustering comes naturally, as participants pick up each other's ideas and make related suggestions. This allows the main themes to be identified by the end of the session (Maguire 2001).

The Imagineering session starts with the facilitator priming the group with a question that concerns the design task at hand and is worded in a way that limits the scope of the ideas to be produced, but does not constrain the group to think about current technologies and practices. The session seeks the generation of ideas about activities rather than technologies of the far future.

A brainstorming session follows based on this question, where the list of ideas is recorded by one of the facilitators on a flip-chart pad. Table \#3 shows examples of priming questions from workshops we have run on various design tasks. It is important that the moderator encourages the participants to focus on the far future, to overcome today's technological restrictions in their thinking. Thus, in the third example in Table \#3 participants were encouraged to think what they would want to be doing in 50 years time with regard to learning about collaborative media making; in the other two examples they were advised to think "space age

In the first two examples in Table \#3 the moderator mentioned that the participants may assume they have available "any kind of gadgets and props" they may need, whereas in the third example there was no direct mention of technology. Much of the responsibility lies with the facilitator to focus the discussion on activity rather than technology, in the future rather than the present (e.g., by asking "what sort of activities would you want to do with this technology?”). 
Table \#3. Example of priming questions used to initiate brainstorming in Imagineering sessions.

\section{Design project: Design future digital imaging technologies \\ $1^{\text {st }}$ Workshop Iteration (objective: generate design ideas)}

Imagine that you are far in the future; that the artefacts you use in your everyday life have evolved and changed. Imagine that you have available there any kind of gadgets and props that you may need to help you to capture and share visual events and experiences. What kind of activities do you think you would want to be able to do in that situation?

Primary activity: to capture and share visual events and experiences

\section{Design project: Design future technology to support informal science learning} $2^{\text {nd }}$ Workshop Iteration (objective: refine ideas produced in first iteration of workshop)

Imagine that you are far in the future; that the artefacts you use in your everyday life have evolved and changed. Imagine that you have available there any kind of gadgets and props that you may need to help you to learn science by exploring your environment now and in the past. What kind of activities do you think you would want to perform in that situation?

THINK SPACE AGE

Primary activity (explored in first workshop): to learn science

Refined activity (outcome of first workshop): learn science by exploring your environment now and in the past

\section{Design project: Design future technology to support collaborative media making}

$2^{\text {nd }}$ Workshop Iteration (objective: generate requirements for future collaborative media making activities and technologies)

Imagine that you are far in the future... and you want to...

\section{LEARN COLLABORATIVELY ABOUT MEDIA MAKING}

But you are so far in the future that the artefacts you use in your everyday life have evolved and changed... As have the media that you want to learn how to make...

What does media making look like? What kind of activities do you perform to learn about it?

Primary activity: learn about collaborative media making

The purpose of the Imagineering session is to set the scene and get the participants to think in terms of the future, with respect not only to technology, but most importantly to the activities and needs that necessitate it. The session acts as a precursor to the modelling session. The outcome of the Imagineering session is a list of envisioned activities (usually complemented by early suggestions for envisioned technology) that people would like to be able to perform in the future. A side effect of this session is that it sets the participants to imagine the far future. 
Session 2 - Modelling

At a glance: Participants create low-tech prototypes of future activity contexts

Duration: 40-50 minutes (time required by small groups to conceptualise and create the prototypes)

Techniques: Low-tech prototyping workshop

Number of Researchers: 2-3, depending on number of participants' sub-groups - making detailed notes of the modelling exercise according to the observation sheet; one researcher also runs the session (introduction, time-keeping, announcements, etc.)

Purpose: To set the participants to imagine the far future and produce models of useful and meaningful technology and activity contexts.

Outcomes: (a) Models produced by the groups and their written descriptions

(b) Videos of the modelling activities and presentations

(c) The facilitators' observation notes during modelling

(d) The facilitators' notes during the groups' presentations

Table 2 grid box: 4 - Future activity and technology

Placement in time: Far future

This session continues the exploration of box 4 in Table \#2, the far future. The participants are divided into two or three groups and are provided with a set of low-tech prototyping materials, such as Play-Doh $\AA^{3}$, coloured pencils and paper, Post-it ${ }^{\circledR}$ notes, and sticky paper. (These are usually the contents one or more children's craft kits, complemented with PlayDoh ${ }^{\circledR}$ and standard stationery items.)

As Buchenau and Fulton (2000) note,

"low-tech solutions seem to promote the attitude that it is the design question that is important, not the tools and techniques that can be brought to bear” (p. 431).

The facilitator asks the groups to confer in order to select one or more of the ideas produced during the first session and to build a model that will demonstrate how the relevant activities are performed. The groups are encouraged to choose different ideas, but this is not compulsory. Asking the workshop participants to work in smaller groups has the advantage that more ideas can be explored; but also gives each participant more chances to influence the designs. As with the Imagineering session, the focus during modelling stays on activities: the groups are instructed to avoid producing detailed designs of technology, but rather to create models of activity contexts along with any necessary technology props. Hence, the focus is on functionality rather than detailed interface design.

Low-tech prototyping has been extensively researched and used in interface design (Virzi 1990). One of the first methods to utilise low-tech prototyping was PICTIVE (Muller 1991), which required design participants to come up with interface designs to given technology solutions. End users are involved in design, however this is after the technology conception phase, so the method fails to support user participation in design innovation:

"for innovative technologies PICTIVE is probably not useful until the technology has been developed to the point that it is ready to be applied to a practical problem" (Muller op. cit., p. 229). 
Other approaches engage users earlier in the design process. For example, Inkpen (1999) involved children in a participatory, low-tech prototyping session to design future handheld technologies that they would like to have. The difference between such sessions and the FTW modelling session is that in the FTW the participants are briefed to shift their focus from the technology itself to what they would like to do with it: their mission is not just to design technology of the future, but to imagine their lives in the future and how technology could support it.

The modelling sessions are video-taped for later analysis. Muller (1991) has identified a valuable role for video records of modelling sessions:

"The video record ... will serve as a dynamic presentation of the design, as a conversational rationale for that design and for the decisions underlying the design, and as a means for communicating concretely the different views of different participants” (p. 226).

However useful they may be, video records are burdensome to analyse: long videos are hard to index and labour intensive to scan. It is therefore recommended that a number of facilitators (one per design group) observe the groups to make notes of the issues, debates and ideas that are produced, together with information about who initiated them and when ${ }^{4}$. The video record then serves as a resource for the analyst for more detailed information as and when necessary.

At the end of the modelling session, the groups are asked to write short descriptions of their models, and to present them to the whole team. Summing up, their model assists the group members to articulate their design and reflect on the modelling experience. The presentations are video recorded while the facilitator(s) make notes for each model about the technology features and functions.

\section{Session 3 - Role Play}

At a glance: The participants build scenarios about the use of the models and act them out Duration: 30 minutes (time required to build and enact scenarios)

Techniques: Scenario building and Role-play

Number of Researchers: At least 1

Purpose: To bring the future into the present, by getting participants to "act" as if future technologies were already there to support new activities, and also to have them engaged in the future activities and make their conceptions of them more tangible.

Outcomes: (a) The videos of the performed scenarios

(b) The facilitators' notes during role-play and scenario discussion

Table 2 grid box: 4 - Future activity and technology

Placement in time: Far future

Continuing the exploration of box 4 in Table \#2, this session asks the groups to exchange models, to plot a scenario demonstrating how the model might be used, and then to enact it. The building and enacting of scenarios have been used extensively in system design. Rosson and Carroll (2003) present different uses of scenarios throughout the system development lifecycle, ranging from capturing requirements and design rationale to guiding formative and summative evaluations. Bødker (1999) discusses three uses of scenarios in design concept 
development: to investigate users' actions with a not yet existing artefact, for focused testing of design ideas or interface aspects, or for providing input to brainstorming about design ideas where the designers get a feeling for use (present and future) by acting out scenarios. She argues that

"good scenarios are not a detached description of user tasks and actions, but selective scripts or stories that stage user actions with a future artefact. They are means of holding on to situations, and how they may be changed because of a design. They represent the reflection over situations, problems or solutions and facilitate action, such as hands-on prototypes or simulations” (Bødker op. cit., p. 8).

Iacucci et al. (2002) emphasise the importance of what they term 'interactional creativity' in scenario building: scenarios developed ad-hoc through the participants' interactions and reactions to each others' input can evolve to address their concerns about, and perspectives of, a given situation.

During the FTW role-play session, the scenario building activity serves all the abovementioned goals. It helps the participant groups to appreciate the possibilities offered by each others' models and to instantiate and explore future use of the models in situations of their choice. Structured scenario-building techniques may be employed, for example the 'who-where-when-what-how-idea' cards discussed in Ihlström et al. (2005). The exchange of models at this stage is important, as it allows a first attempt at exploring the appropriation of new technology, as a consequence of its introduction into people's lives. Iacucci et al. (2002) argue that "one of the aims of design is to deliver systems that can be appropriated by people in real life" ( $p$ 175), and the phenomenon of tool appropriation has been documented in research by Waycott (2004). Furthermore, while working with someone else's design the participants can be more critical than if working on their own designs to which a certain degree of 'emotional attachment' might exist. Finally, the models have the chance to benefit from all participants' perspectives and agendas rather than only from the sub-group of participants who designed them, allowing possible conflicts to surface and be considered.

The subsequent acting out and discussion of the scenarios allows the participants to communicate, and receive feedback on, their conceptualisations to the rest of the team. At the same time, the participants are called to actively 'live' the situations they have envisaged, to have as close to first-hand an experience of the envisioned context of use as possible. Iacucci et al. (2002) identify three roles for performances in the design process: to explore new ideas through acting out scenarios; to communicate new concepts and designs to prospective customers for early feedback or to design teams for further concept development; and to test design ideas with prospective users who may discover problems and make suggestions for improvements. The role-play in FTW serves all of these roles, with the last one made possible by allowing the rest of the team to comment on the scenario that is played out.

The combination of the modelling and role-play sessions resembles what Buchenau and Fulton (2000) designate as Experience Prototyping, which they describe as representations designed to understand, explore or communicate what it might be like to engage with the product, space or system that is designed.

After a group has role-played a scenario, the group that had originally designed the model is asked whether the enactment matched their initial conception of the model, what differences 
they can see, and any related issues. This typically short discussion aids the consolidation of views and perspectives in the feedback gained.

As with the modelling session, the role-play session is documented on video and in structured notes taken by the facilitators, on specially formatted paper, covering the activities presented, the actors, their consequences in terms of the plot, and the outcomes in terms of the involved technology. In addition, the facilitator(s) make structured notes of the differences between the designers' and performers' conceptions of the models.

\section{Session $4-$ Retrofit}

At a glance: The participants modify the scenarios so as to make use of existing technology only

Duration: 30 minutes (time required to modify and enact scenarios)

Techniques: Scenario building and Role-play

Number of Researchers: At least 1

Purpose: To bring the future into present everyday life, setting the participants to think how the futuristic activities they have imagined so far might be adapted into their current lives.

Outcomes: (a) The videos of the performed scenarios

(b) The facilitators' notes during role-play

(c) A list of the identified technological gaps for supporting future activities

Table 2 grid box: 3 - Future activity with current technology

\section{Placement in time: Present}

This session explores box 3 of the grid in Table \#2 and is situated at the present time. In Retrofit, the groups are asked to modify their scenarios from the previous session so that any use of futuristic technology is omitted and they only make use of existing technologies in their stories. This is an exercise to ground the 'visionary' work the participants have done in the previous sessions back in reality. The participants are invited to see the relevance of the future to the present, to explore whether they can already do the future activities they have envisioned without the need for new technologies, to estimate how difficult or complicated that would be, and to appreciate how new technology might improve life. Scenario modification and performance play the same roles as scenario building and performance in the previous session.

To facilitate the participants in thinking about currently available technology, a range of relevant existing technologies can be displayed together with gadget catalogues, and basic functionality can be described (for example, in the workshops for digital imaging, technologies such as digital and analogue still and video cameras were set out on a table and were available for use in the scenarios ${ }^{5}$ ). Prototypes that have been constructed based on previous workshop iterations may also be demonstrated at this stage.

The Retrofit session is documented in a similar way to the Role-play session, with the only difference being that, instead of documenting the debate between model designers and performers at the end of the role play, the facilitators make notes of future activities that are not supported at all, or not supported adequately, by existing technology as these may be areas that afford the introduction of new tools. 
Session 5 - Everyday

At a glance: The participants list their current activities and problems in carrying them out. Duration: 10-15 minutes (time required to produce a diverse list of current activities and related problems)

Techniques: Group discussion

Number of Researchers: At least 1

Purpose: To get participants thinking about their current practices in relation to the design task and how they could be improved in the future.

Outcomes: (a) A list of current activities performed using current technology

(b) A list of related problems

Table 2 grid box: 1 - Current activity with current technology

Placement in time: Present and recent past

This session explores box 1 of the grid in Table \#2 and is situated in the present and recent past. The participants, working as a single group, are asked to list ideas about what activities they currently perform using existing technology, in relation to the design activity that was introduced in session 1 (for example, to capture and share visual events). To facilitate thinking, the facilitator shows the group photos of current technologies (for example, pictures from a technology catalogue) and demonstrates existing gadgets relevant to the design task, as in the Retrofit session. The participants are then asked to think back to related activities that they performed in the last few weeks. Once a list of current activities is produced, the participants are then asked to identify relevant problems and shortcomings of the existing technologies and practices. The facilitator(s) notes the current activities and problems in two columns on a flip-chart and the sheet remains on display for the remainder of the workshop.

Gaver, Dunne, and Pacenti (1999) proposed the use of 'cultural probes', which are kits of materials such as disposable cameras and diaries, as a means to inspire people to reflect on their lives in different ways. Instantiating the technique in technology design, Hutchinson et al. (2003) proposed the use of 'technology probes', which are prototypes of some piece of (new) technology, as a means to encourage people to reflect on their everyday practices and conceive of new uses and functionality for technology. The Everyday session in the FTW serves the purpose of reminding participants of what activities they currently perform and the problems they face in operating current technology. Since this is done in the context of the preceding sessions where participants were envisaging new technologies and activities, the Everyday session serves as a probe itself, encouraging reflection on the gap between where the participants currently are and where they want to go.

Session 6 - Futurefit

At a glance: The participants modify their models to support current as well as future activity, and try to 'sell' them to the rest of the team.

Duration: 50-60 minutes (time required to modify models and 'sell' them)

Techniques: Brainstorming, Scenario building, Performing

Number of Researchers: At least 1

Purpose: To set the participants thinking about what types of future technology will be used to support the activities they currently perform, as well as to obtain a list of implicit requirements for technology based on the way the models are advertised.

Outcomes: (a) List of near-future technologies to support current activities 
(b) List of implicit requirements (what the designed models can do and what the 'prospective customers' appear to want them to do)

Table 2 grid box: 2 - Current activity with future technology

Placement in time: Near future

Session 6 explores box 2 of the grid in Table \#2 and is situated in the near future. The group is asked to look at the current activities and problems that were produced in the previous session and discuss how they think those current activities will be performed in the near future. During a brainstorming activity, the whole team produces a list of future technologies that will address the problems they have with their existing practices. The facilitator records on a flip-chart the ideas that are produced.

Next, the facilitator prompts the participants to think of the envisaged solutions in relation to the models they had built earlier: the groups are prompted to think about technology and activity that will be achievable in the next five years, and are asked to modify their initial models to accommodate as many of the current activities identified as possible while solving as many related problems as possible, and still supporting the previously envisaged activities. This session blends the present and the future and encourages participants to create a 'unified' vision of emerging technologies and activities.

The participant groups are then asked to devise an advert for their modified models and present it for the other groups in order to convince them to 'buy' their product. The other groups have the chance to say whether and why they would buy it or not. This selling exercise is documented by the facilitator, who makes notes on a flip-chart about what each group considers to be the strong points of their model (as emphasised in the advert), as well as the main points made by the replies from the 'customers' and the 'designers'. These notes can be the basis for producing a list of implicit requirements, based on what the participants consider to be important features of each model.

\section{Session 7 - Requirements}

At a glance: The participants list requirements for future technology

Duration: 15-20 minutes (time required to examine models and scenarios and list requirements)

Techniques: Focus group discussion

Number of Researchers: At least 1

Purpose: To get participants to explicate their requirements for future technology

Outcomes: An explicit list of requirements for future technology

Table 2 grid box: 2 and 4 -Future and current activity with future technology

Placement in time: Near future

This session relates to boxes 2 and 4 of the grid in Table \#2 and is concerned with requirements for new technology and activity in the near future. The whole group is asked to produce a set of requirements for each model, based on their experience of the previous sessions and their needs. Requirements are described to the participants as the set of instructions they would give to an engineer who would be willing to implement the model. The group is also asked to identify the two most important requirements for each model, and are then asked to rate individually the requirements on a scale between 1 and 5, with 5 having the most importance/appeal. 
The Requirements session is the climax of the Future Technology Workshop. Through the preceding sessions, the participants have imagined, modelled, and experienced activities and technologies of the future. This route has enabled them to reflect and gain insights into what activities in the far future might be like in relation to the design task at hand, thus preparing them to specify their requirements for emerging, or near future technology with sufficient accuracy.

\section{Timing and participants}

Smith (1998) divides the design process of new-generation products into three stages: Exploratory Design, Concept Refinement and Analysis, and Formal Design. The Future Technology Workshop targets primarily the first stage, Exploratory Design, which aims to identify and conceptualise potential new high-value products and services. Thus, the best time to conduct an FTW is during product conception, as it offers a user-centred, structured approach to creativity and innovation in concept development.

The choice of participants for an FTW depends on the purpose of the workshop. End users, 'everyday people' with no personal agendas with regard to the workshop objective, promise more impartial input. Involving those whom von Hippel (1986) calls 'lead users', (users who face needs that will be general in the marketplace, but face them months or years before the bulk of the marketplace encounters them; and who will benefit significantly by obtaining a solution to those needs) can be advantageous, as

"although the insights of lead users are as constrained to the familiar as those of other users, lead users are familiar with conditions which lie in the future for most - and so are in a position to provide accurate data on needs related to such future conditions" ( $p .796)$.

Involving designers as well as end users guarantees an element of feasibility in the resulting concepts. For specialised areas, the involvement of experts pays off in terms of informed concepts; for example, involving educational experts when the objective is to design tools for learning. Different types of participant can be involved in a single workshop, maintaining mixed participant groups. Alternatively, iterations of the workshop with different participant groups can build on previous workshop outcomes. Furthermore, 're-using' participants from participant groups in future FTW iterations can be useful, as they have had time to reflect on their ideas and practices and provide more 'mature' input than new participants.

\section{Examples of the use of Future Technology Workshops}

The Future Technology Workshops has been successfully adopted by ourselves and others in a variety of projects, with both children and adults. A summary of some applications of the method follows. They show its use a) with children leading to the design of an innovative product, b) with adult volunteers as part of requirements gathering for a major technology design project, c) with research academics to envision future scenarios for learning, and d) with children to engage them in technology design. 


\section{FTW for 'capturing and sharing visual events'}

The FTW was developed during the Children as Photographers project (Sharples, Davison, Thomas, \& Rudman, 2003), where we undertook a series of five workshops with children aged 10-13 (Vavoula et al.. 2002; Vavoula, Sharples, Cross, \& Baber, 2003) and adults, focusing on the theme of future activities and technologies related to capturing and sharing visual events and experiences.

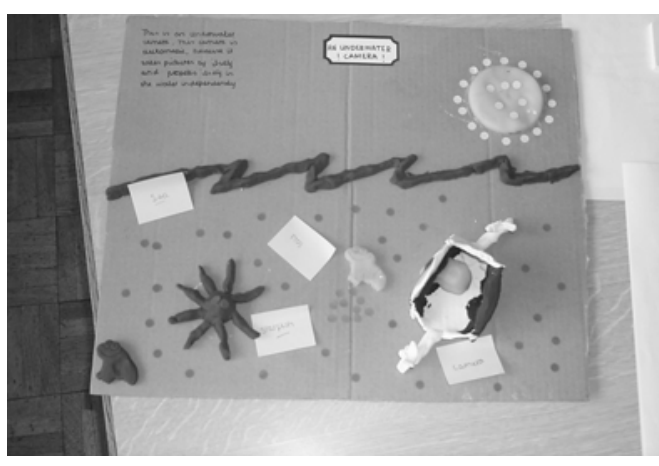

(a)

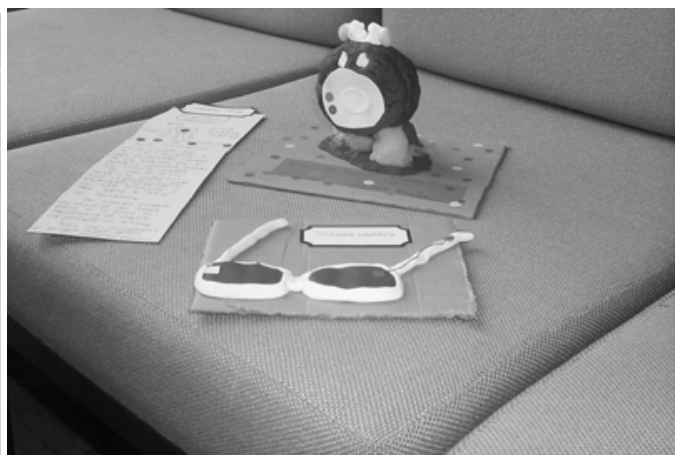

(b)

Figure \#2. Models produced by children (aged 10-13) who participated in FTWs for 'capturing and sharing visual events': (a) The 'Underwater Camera' - a camera than can be remotely controlled while it explores the deep sea and sends back images to its owner, (b) The Mobile MemoCam (top) - a camera with autonomous movement that can remember where items of interest are and can go to photograph them; and SpyGlasses (bottom) -.a miniature camera is hidden in the glasses frame, allowing the owner to take photographs spy-style.

The main concepts that the children devised during the first two workshops were those of 'spy' cameras (miniature cameras hidden on the body that can capture everyday events, or relay the images to another person) and 'robot' cameras, where a camera is attached to another person, an animal or an object such as a remote control submarine, with the images viewed at a distance (see Figure \#2a, b). The outcomes of these workshops were complemented with an additional two workshops with adults, one on the same theme of capturing and sharing visual experiences, and the other on a theme that emerged in the previous workshops on "getting immersed in the sights and sounds of another place and/or time”. The general requirements that resulted from all five workshops can be summarised as follows:

- Ability to view the world through the eyes of another person or other living being

o Ability to capture that view

o Ability to intervene in / control that view

- Ability to share experience instantly

- Ability to share not only visual experience but other modalities too (sound, touch, smell, etc.)

- Record of personal experience over a lifetime

- Automatic, prompt availability without the need for switching on, logging in, etc.

- Fast enough to capture the moment instantly

- Discreet / secret / unobtrusive technology 
- Durable, portable, reliable

- Cheap

A team at the University of Birmingham then built a "SpyCam" device that combined elements of both the spy and remote camera, based on the requirements listed above (Vavoula et al. 2003). The prototype consisted of an inexpensive wireless mini colour camera, mounted on a pair of sunglasses (see Figure \#3a, b), which transmits a colour composite video signal to a portable computer (a Panasonic Toughbook) that has a separate wirelessly connected handheld screen. Thus, the camera and the view screen can be carried separately, each with a range of about 100 metres from the base-station. We used the SpyCam in two configurations. In the first, one child wore the glasses and another held the Toughbook screen. The child with the screen had a continuous transmission of what the other child was seeing, and could tap the screen at any time to capture a still frame (for example, a child holding the screen could see what another child saw as she was going down the zip wire at a holiday camp). The children were able to communicate by voice through 'walkie-talkie' handheld radios. This configuration exemplified the remotely controlled camera idea. In the second configuration, a child wore the glasses with the attached camera and also had a wireless remote control keyfob. A press of the key-fob button sent a command to the Toughbook to take a picture. This configuration exemplified the spyglasses camera idea (see Figure \#3a).

Different scenarios were tested for both configurations, with 32 children at a residential education and activity centre, none of whom had participated in an FTW. We also carried out tests using two blindfolded treasure hunt games, designed to exploit the features of the SpyCam prototype. The trials revealed that the children found no difficulty in operating the equipment.

All the children gave very positive responses to the question of whether they enjoyed it, for example:

"It was just like, you didn't have to worry about holding it or nothing it was just, always on you and easy to use, because if you wanted to take a photo just tell them, just push the button" (boy, age 13)

"I liked that you could see what they were seeing instead of just seeing what you could... instead of just looking at them and trying to imagine what they could see" (girl, age 11)

What seemed to impress them the most was the ability to see what someone else was seeing in real time, the ability to control where someone else goes, the need to trust someone's instructions on how to move and what to do, and the choice of whether to take a photograph or not. The new possibilities offered by the concepts that emerged from the FTW were enjoyable, fascinating new activities for the children who tried them.

The third and final children's workshop (fifth workshop in total) was carried out with a different group of six children, again three boys and three girls. This workshop built on the outcomes of the previous ones, with the children being shown the prototypes and asked how they could be altered or improved during the 'retrofit' and 'everyday' sessions. The design task therefore related to "capturing visual events remotely, without being noticed". The children converged on a design that includes a camera which can attach to a variety of objects such as sunglasses and wrist watches. Our initial prototypes were therefore expanded to 
include, besides the SpyCam on the sunglasses, a RoboCam employing a model car operated by remote control with the miniature camera mounted on top. The camera can easily be removed from the glasses frame and attached to the roof of the car, which the children can then operate by the remote control and receive the image from the camera on to a computer monitor or on a small-screen TV.

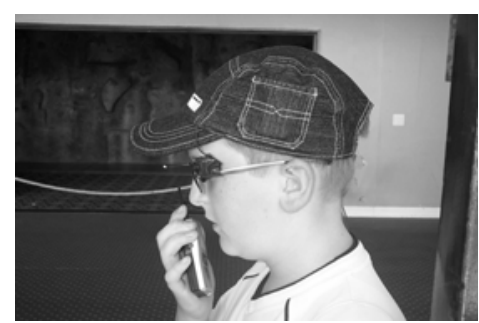

(a)

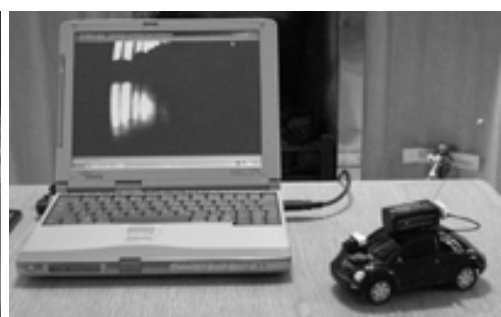

(b)

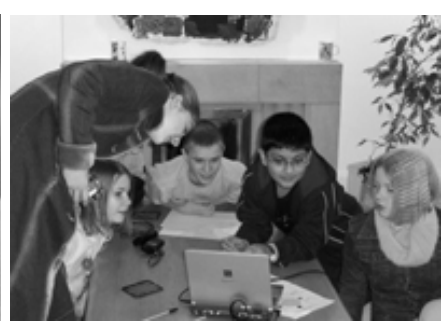

(c)

Figure \#3. Prototypes developed based on the ideas and requirements produced during FTWs for 'capturing and sharing visual events': (a) The 'SpyCam' - child wearing sunglasses with miniature camera mounted on, which transmits a video signal to a Panasonic Toughbook that has a separate wirelessly connected handheld screen. The screen is held by another child (not shown in the photo) who can see the view from this child's camera. Audio communication between the two children is enabled by walkie-talkies (shown in child's hand). (b) The 'RoboCam': a miniature camera is attached to roof of a model car which can be operated by remote control (not shown). The signal from camera is received on to a computer monitor, which children not co-located with the model car can inspect. (c) Children are gathered around the RoboCam control table, looking at the image transmitted from the roof of the model car (not shown). The model car is controlled by another child (not shown), who receives requests and suggestions on how to manoeuvre the car via walkie-talkie.

The new prototypes were tested with the same six children who participated in the second workshop, in two scenarios. The first scenario was a blindfolded treasure hunt, where one child was blindfolded and wore the spyglasses and the other children instructed her to wander around another room and collect clues. The second scenario involved collaborative solving of a mystery and made use of the RoboCam. Six pieces of paper containing key information about the mystery were put around a room different to the one where the children were, at floor level. One child navigated the RoboCam through the remote control, and the other five children watched the image sent by the RoboCam and instructed the navigator-child where to send the car (see Figure \#3c).

The children enjoyed both scenarios and had no trouble in operating and making use of either the SpyCam or the RoboCam. As with the previous trials, shortcomings of the technology in terms of performance were not off-putting and the children were more interested in the live image than the photographs they were able to capture. The same children then participated in the final children's workshop. They were asked to go through the workshop refining the designs and expanding the ideas of the RoboCam and the SpyCam. The imagineering session mainly produced a list of things on which the SpyCam could be mounted: briefcases, wristwatches, sunglasses, dog collars, model boats and many more.

In summary, the FTW was successful in producing requirements for novel and implementable technology for children. New digital imaging devices were designed and prototyped from 
requirements generated by two iterations of the FTW method. Thus, the method fulfills the initial aim of fitting within a process of human-centred systems development while generating designs and requirements for radically new technology.

\section{FTW for 'training First Aid volunteers'}

The FTW was adopted by the MOBIlearn project, funded by the European Commission Information Society Technologies programme, for the design of mobile technology for learning. One scenario in MOBIlearn was to aid the training of adult first-aid volunteers (Evans and Taylor 2004, Sharp, Rogers \& Preece 2007). Whereas the focus in the Children as Photographers project was to develop new product concepts, in MOBIlearn the objective was to produce general requirements for mobile support of trainee first-aiders. The participants were first-aid volunteers from the Open University, UK, and the models they produced included, among others, a 'diagnostic machine': a kit that, when applied to the person in need, assesses their situation accurately and assists the first-aid worker to report the incident appropriately. To produce the requirements, all the FTW sessions were transcribed and the transcripts were analysed by identifying current and future tools and artefacts and their use (Mwanza, Taylor, Sharp, \& Vavoula, 2003). These were then translated into design requirements and recorded in a structured format, along with MOBIlearn requirements from other sources (Sharp et al. 2003; Haley, Nuseibeh, Sharp, \& Taylor, 2004; Taylor 2004). The FTW method was useful in informing the requirements gathering process for MOBIlearn, Although the 'diagnostic machine' concept was not developed further, requirements developed at the workshop, such as incorporation of 'scanners' for capturing and storing information, were included as requirements for the MOBIlearn system.

\section{FTW for 'informal science learning in mobile settings'}

As part of a project (MELISSA) within the Kaleidoscope European Network of Excellence (www.noe-kaleidoscope.org), we investigated informal science learning in mobile settings (Vavoula et al. 2005a). The participants in this FTW were ten members of the project research team, plus two external experts in mobile learning.

The FTW focused on the design of future technologies and activities related to learning in informal science settings. Two main models were developed, including a model featuring 'whisperers' (agents that sit on a user's shoulder and whisper in their ear information about their social context), and one featuring 'zoom and time travel' (while moving around an urban setting, a person has the opportunity to zoom into some part of that environment, moving from a macro to a micro view, to understand how it is constructed; and they can also 'travel back in time' to see what that environment looked like in the past). The two models were developed further during the FTW sessions, concluding with a list of general requirements for each model. The requirements produced during the FTW formed the input for a force-field analysis (Thomas 1985), a focus group method for the identification of 'helpers' and 'hinderers', i.e., factors that contribute towards or against achieving the vision specified by the requirements. Later, the models produced were examined in relation to specific learning theories in order to identify how they fit with each theory.

Within this project, the FTW was successfully used for a different purpose to the previous ones, namely to envision the future of a research area. Starting with summaries of extensive reviews of the area, involving domain experts, and augmenting the workshop with additional 
sessions such as the force-field analysis and the theory-fit, the result was a well-informed vision of requirements for informal science learning in the future (Vavoula, Lonsdale, Mwanza, Scanlon, \& Hardy, 2005b).

\section{Evidence of success}

The case studies presented in the previous section described how the FTW was used in the Children as Photographers project for concept design (Vavoula et al. 2003); in the MOBIlearn project as a requirements analysis method (Sharp et al. 2007); and in the MELISSA project as a means to conceptualise the potential of a new type of technology (i.e., mobile technology) in supporting learning.

The FTW has directly informed the design of prototypes that are 'engineerable' in that they could conceivably be realised through present-day engineering methods. Two of these prototypes have been implemented and tested with children, as described in the first case study.

The costs for running a FTW are minimal: any room with enough space to comfortably fit the participant groups is adequate; the materials used (craft kits) are low-cost; and the training required for the participants is limited to presenting them with a set of instructions at the start of each session. Although it is recommended that certain sessions are videotaped, the hand notes on specially formatted paper also speed up the analysis process with the first results readily available at the end of the requirements session. This enables FTW to be adopted for commercial projects requiring rapid development.

In the introduction we set out requirements for a design method that is aimed at the conception and design of radically new or disruptive technologies: technologies that empower learners, workers and other users to realise their aspirations for new, desirable activities. The Future Technology Workshop meets all these requirements:

a) Minimal participant training. We have used the FTW in projects with adults and children with no prior training in software design. In all cases participants have been able to envision, enact and analyse collaborative interactions with new technologies after only brief descriptions of what each workshop session involves.

b) Collaborative. The FTW is designed to explore and design group activities for learning and creativity. All the sessions are group-based and include whole-group idea generation, small-group modelling and role-play, and whole-group critique, discussion and requirements forming.

c) Direct input to design. The FTW integrates well with the socio-cognitive engineering approach described in the introduction to this paper. The sessions have produced requirements for technology that has been successfully engineered and deployed.

d) Cost-effective to run. The FTW has no specific requirements for the room where it takes place as long as it can accommodate the required number of participants and can offer quiet corners for small group work. The workshop does not involve the use of expensive equipment and can be run in any adequately sized meeting room. It can be run in half day.

e) Relates people and technology. The FTW starts with a focus on what participants would like to be able to do in the future and the focus throughout the workshop remains 
on the socio-technical systems they envision (rather than on the technology involved) through predicting and refining contexts and situations of use.

f) Open-ended. The FTW starts by giving participants a very broadly defined activity area rather than a specific design objective. Thus, participants are free to explore and define the form and scope of the new socio-technical system in an open-ended manner.

g) Pragmatic. Although the first three FTW sessions are placed in the far future where participants are free to envision socio-technical systems that include fanciful and impracticable technologies, the following sessions ground these visions in the present and encourage participants to project the present and the far future into the near future to end up with visions that can conceivably be designed by practical present-day engineering methods.

The FTW enables participants to envision emerging socio-technical systems as opposed to new technologies intended only to replace existing ones in established practice. It provides a framework for the systematic envisioning of such systems by taking participants on an exploration of the far future, through the present and recent past, to reflect upon their needs and aspirations and conceptualise what is desirable but also achievable in the near future. In this sense, the FTW puts together well established design techniques in a novel way that can directly and creatively inform design.

We have systematically evaluated the participant experience through questionnaires administered after each FTW, The responses show that participating in a FTW is an enjoyable and interesting activity. Some typical responses are shown below:

"When people are relaxed they tend to think in a more free-form way. I enjoy the brainstorming that goes on, which often begins with fun and laughter, but which then begins to focus and home in on some really interesting ideas"

"The need to represent the imagined situation by means of a kind of 'art work' and a short play helped to make the imagination activity more concrete and more live. The fact that the play had to represent the situation imagined by another group stimulted me to pay more attention to other people visions that I would have done otherwise."

"The whole thing is very coherent - each stage leads to the next - and at the end it feels as though a cycle has been completed ... I think it makes good use of the expertise and skills of the group involved - so that the whole is more than the parts”

"It's a very useful method for thinking 'outside the box' but also grounds that thinking back in reality, theory etc."

However, some participants also expressed concerns about the 'playfulness' that the workshop sessions infuse:

"(I liked) the distraction of the materials and the social engagement... but it did distract from the 'issue(s)'”,

"The fun bit can be a disadvantage because people can get carried away in playfulness and fail to connect the significance of activities to the design process"

Much of the responsibility to keep participants on track, albeit within a fun and enjoyable atmosphere, lies with the moderator(s) who need to discretely and continually observe the 
participant groups and make interventions when a group seems distracted from their task for a prolonged time.

A potential limitation of the method is that the results of an FTW are based on technology in an imagined context. It is inevitable that the designs will be out of context, since the objective of an FTW is to design disruptive technology that changes or introduces new practice. Removing participants from their everyday settings and exploring new contexts of use is necessary if they are expected to re-conceptualise their needs and practices. Attention therefore needs to be paid to the validation of FTW outcomes by, for example, combining FTW iterations from different participants along with focus groups, user surveys, and other methods of observing user practices in everyday contexts.

In our applications of the FTW so far we have mainly used it to understand the possibilities for interactions between new technologies and new types of activity in the future. It may thus be argued that an implicit assumption is made that technology is a natural solution to problems. In fact, this implicit assumption might lie behind all system design, otherwise attention would be turned to devising other kinds of solution. However, the FTW recognises the need to analyse the role this technology will come to play in people's lives, by problematising whether, and if so how, people's aspirations might be satisfied by technology.

\section{Conclusions}

The Future Technology Workshop (FTW) offers a context in which people with knowledge or experience in a specific area of technology use, explore and design the interactions between current and future technology and activity. The FTW provides a framework for the systematic envisioning of emerging socio-technical systems by taking participants on an exploration of the far future, through the present and recent past, to reflect upon their needs and aspirations and conceptualise what is desirable but also achievable in the near future. Through a series of structured workshop sessions participants collaborate to envisage future activities related to technology design, build models of use contexts of future technologies, act out scenarios of use for their models, re-conceive their scenarios in relation to present-day technologies, list problems with carrying out the scenarios, explore the gap between current and future technology and activity, and end by listing requirements for future technology.

The method has been used successfully with children and adults to explore new technologyactivity systems including interacting with images and informal science learning. Our experience with FTW shows that it is a cost-effective collaborative design method, as it requires inexpensive tools and resources, and minimal participant training. While it does not presume fixed patterns or contexts of use, it still yields engineerable outcomes that can directly inform design. The FTW provides a framework for creativity that is focused on relating people with technology, by emphasising the envisioned socio-technical systems rather than technology.

Many well-established design methods are grounded in an analysis of current everyday activity in learning and/or work settings. These will continue to be relevant and useful for improving existing practices with technology, but are not appropriate for developing radically new or disruptive devices that overturn current technologies (Bower \& Christensen, 1995). Nor are they suited to envisioning how people might learn, work or play together in a future 
of pervasive computing. The FTW provides one way for exploring and designing such futures. The next steps for FTW and similar methods will be also to provide the means for further challenging those futures, by subjecting them to a cycle of refinement and reinvention.

\section{Acknowledgements}

We are grateful to Chris Baber, Josie Taylor, Patrick McAndrew, Peter Lonsdale and Daisy Mwanza for useful feedback and comments on the FTW. We thank James Cross for his work in developing the prototype camera technologies. Thanks are also due to all those who took part in our workshops as facilitators or participants. We should also like to thank the anonymous reviewers who helped us to focus and improve the paper. The method was developed as part of the Children as Photographers project, funded by Eastman Kodak Corporate Contributions Fund, and the MOBIlearn project, funded through the European Commission Framework 5 Programme (www.mobilearn.org).

\footnotetext{
${ }^{1}$ Imagineering is a term coined by R.F Sailer in 1957 and trademarked by a Disney partner company to describe the process of engineering a future of the imagination.

${ }^{2}$ During some of the workshop sessions, the participants work in subgroups, thus a minimum of 6 participants guarantees at least three subgroups of two; for the rest of the sessions the participants work in a single group, making it difficult to work effectively with more than 20 people.

3 "Play-Doh ${ }^{\circledR}$ is a non-toxic compound similar in texture to bread dough that has been sold as a children's toy around the world for over half century.” (http://en.wikipedia.org/wiki/Play-Doh).

4 The FTW kit (available to download at www.ftw.org.uk) contains templates to aid facilitators in taking observation notes during those workshop session where note taking is necessary.

${ }^{5}$ We should note that the first Future Technology Workshops on the "capturing and sharing visual experiences" topic took place in 2000 - 2001; at that time, camera phones were not widespread in Europe (they were introduced in the US market in 2002), and other personal media sharing environments and tools such as MySpace, Flickr and Instant Messaging were not available.
}

\section{References}

Arvidsson, F., Ihlström, C. \& Lundberg, J. (2002) Vision of future news - Consensus or conflict? Proceedings of the 25th Information Systems Research Seminar in Scandinavia. CD-ROM. Bautahøj, Denmark, August 10-13, 2002.

Beyer, H., \& Holtzblatt, K. (1998) Contextual Design: Defining Customer-centered Systems. Morgan Kaufmann Publishers, San Francisco. CA.

Bo, G. (2005) MOBIlearn: Project Final Report. Available at http://www.mobilearn.org/results/results.htm. Accessed 14th June 2007.

Bødker, S. (1999). Scenarios in user-centred design: Setting the stage for reflection and action. Proceedings of the 32nd Hawaii International Conference on System Sciences, Maui, HI, January 1999. IEEE, New York.

Bower, J. L. \& Christensen, C. M. (1995). Disruptive Technologies: Catching the Wave. Harvard Business Review, January-February 1995.

Bruseberg, A., \& McDonagh-Philp, D. (2001). New product development by eliciting user experience and aspirations. International Journal of Human-Computer Studies, 55, 435452.

Buchenau, M., \& Fulton, J. (2000). Experience prototyping. Symposium on Designing Interactive Systems 2000, Brooklyn, NY, August 2000, ACM Press, 424-433. 
Delbecq, A.L., Ven, A.H. \& Gustafson, D. (1975). Group Techniques for Program Planning: A Guide to Nominal Group and Delphi Processes. Glenview, Illinois: Scott, Foresman \& Co.

Druin, A., Bederson, B., Boltman, A., Miura, A., Knotts-Callahan, D. \& Platt, M. (1999). Children as our technology design partners. In Druin, A. (ed) The design of children's technology. San Francisco, CA: Morgan Kaufmann Publishers, pp 51-72.

Ehn, P. \& Kyng, M. (1991). Cardboard computers: Mocking-it-up or Hands-on the future. In Greenbaum, J. \& Kyng, M. (eds) Design at work: Cooperative design of computer systems. New Jersey: Lawrence Erlbaum Associates, pp 169-196.

Evans, D., \& Taylor, J., (2004). The role of user scenarios as the central piece of the development jigsaw puzzle. In J. Attewell \& C. Savill-Smith (eds.) Proceedings of MLearn2004: Mobile Learning Anytime Everywhere. Learning and Skills Development Agency, London, UK.

Gaver, W.W., Dunne, A., \& Pacenti, E. (1999). Cultural probes. Interactions Magazine. vi, 1, 21-29.

Haley, D., Nuseibeh, B., Sharp, H., \& Taylor, J., (2004). The conundrum of categorizing requirements: Managing requirements for learning on the move. Proceedings of 12th International Requirements Engineering Conference (RE'04), Kyoto, Japan, 6-10 September 2004, IEEE Computer Society Press (pp. 309-314).

Herstatt, C., \& von Hippel, E. (1992). From Experience: Developing New Product Concepts Via the Lead User Method: A Case Study in a "Low Tech" Field. Journal of Product Innovation Management, 9, pp 213-221.

von Hippel, E. (1986). Lead users: A source of novel product concepts. Management Science, 32(7), 791-805.

Hutchinson, H., Mackay, W., Westerlund, B., Bederson, B., Druin, A., Plaisant, C., Beaudouin-Lafon, M., Conversy, S., Evans, H., Hansen, H., Roussel, N., Eiderback, B., Lindquist, S. \& Sundblad, Y (2003). Technology Probes: Inspiring design for and with Families. Proceedings of Conference on Human Factors in Computing Systems (CHI 2003). ACM Press (pp. 17-24).

Iacucci, G., Iacucci, C., \& Kuutti K. (2002). Imagining and experiencing in design, the role of performances. Proceedings of NordiCHI, Aarhus, Denmark, Oct 19-23 (pp. 167-176).

Iacucci G., Kuutti, K., \& Ranta M. (2000). On the move with a magic thing: role playing in concept design of mobile services and devices. In Proceedings DIS2000, Designing Interactive Systems, New York City: ACM Press 2000, pp 193-202.

Ihlström, C., Svensson, J., \& Åkesson, M. (2005). Participatory design of future every day IT artifacts - Engaging readers and publishers in designing the e-newspaper. In Proceedings of the 28th Information Systems Research Seminar in Scandinavia, Norway. CD-ROM.

Inkpen (1999). Designing handheld technologies for kids. Personal Technologies Journal, 3(1-2), 81-89.

Jonassen, D.H., Tessmer, M., \& Hannum, W.H. (1999). Task Analysis Methods for Instructional Design. Lawrence Erlbaum, New Jersey.

Jungk, R. \& Müllert, N. (1987). Future Workshops: How to Create Desirable Futures. London: Institute for Social Inventions.

Kensing, F. (1987). Generation of visions in systems development. In Docherty, P., FuchsKittowski, K., Kolm, P., \& Mathiasen, L. (Eds.), Systems design for human and productivity - Participation and beyond. Amsterdam: North-Holland, pp. 285-301. 
Kensing, F., \& Madsen, K.H. (1991). Generating visions: Future workshops and metaphorical design. In J. Greenbaum \& M. Kyng (eds.), Design at work: Cooperative Design of Computer Systems. Lawrence Erlbaum, Hillsdale NJ, pp. 155-168.

Maguire, M. (2001). Methods to support human-centred design. International Journal of Human-Computer Studies, 55, 587-634.

Muller, M.J. (1991). PICTIVE - An exploration in participatory design. In Robertson, S.P., Olson, G.M. \& Olson, J.S. (eds), Proceedings of the SIGCHI conference on Human factors in computing systems: Reaching through technology, New York, NY, USA, ACM Press (pp 225-231).

Muller, M.J. \& Kuhn. S. (1993). Participatory design. Communications of the ACM, 36(6), 24-28.

Mwanza, D., Taylor, J., Sharp, H. \& Vavoula, G. (2003). Methods for abstracting design requirements for a mobile e-Learning environment. In Blake, C.T. \& Lack, K. (eds), Proceedings of CALRG Conference 2003, Milton Keynes, UK, Jul 2-3 (pp. 8), The Open University. http://kn.open.ac.uk/public/getfile.cfm?documentfileid=3399

Osborne, A.F. (1963). Applied Imagination. Schribeners and Sons, New York.

Rosson, M.B., \& Carroll, J.M. (2003). Scenario-Based Design. In Jacko, J.A., \& Sears, A. (Eds) The Human-Computer Interaction Handbook. Lawrence Erlbaum Associates.

Salvador, T., \& Sato, S. (1998). Focus Troupe: Mini Workshop on Using Drama to Create Common Context for New Product Concept End-User Evaluations. In Proceedings of Participatory Design Conference, Seattle, CPSR, pp. 197-199.

Sanders, E.B.-N. (2000). Generative tools for co-designing. In Proceedings of CoDesigning 2000. London: Springer, pp. 3-12.

Scaife, M. \& Rogers, Y. (1999). Kids as informants: Telling us what we didn't know or confirming what we already knew? In A. Druin (ed.), The Design of Children's Technology. San Francisco, Morgan Kaufmann, 27-50.

Schwartz, P. (1997). The Art of the Long View: Planning for the Future in an Uncertain World. Wiley, Chichester.

Sharp, H., Rogers, Y., \& Preece, J. (2007). Interaction Design: Beyond Human-Computer Interaction. John Wiley and Sons Ltd, $2^{\text {nd }}$ edition.

Sharp, H., Taylor, J., Lober, A., Frohberg, D., Mwanza, D., \& Murelli, E., (2003). Establishing user requirements for a mobile learning environment. In Proceedings of Eurescom Summit 2003, Evolution of Broadband Services, Heidelberg, Germany, 29 Sep - 1 Oct 2003.

Sharples, M. (1987). The Design of a User-friendly System. In A. Jones, E. Scanlon, T. O’Shea (eds.), The Computer Revolution in Education: New Technologies for Distance Learning, Harvester, pp. 65-79.

Sharples, M., Jeffery, N., du Boulay, J.B.H., Teather, D., Teather, B., \& du Boulay, G.H. (2002). Socio-cognitive engineering: a methodology for the design of human-centred technology. European Journal of Operational Research 136, 2, pp. 310-323.

Sharples, M., Davison, L., Thomas, G.V., \& Rudman, P. D. (2003). Children as Photographers: an Analysis of Children's Photographic Behaviour and Intentions at Three Age Levels, Visual Communication, 2(3), 303-330.

Sharples, M. (2006). Socio-cognitive Engineering. In C. Ghaoui (ed.) Encyclopedia of Human-Computer Interaction, Hershey: Idea Group Reference, pp. 542-547.

Smith, C. (1998). Transforming user-centered analysis into user interface: The design of newgeneration products. In L.E. Wood (ed.), User Interface Design. Bridging the Gap from User Requirements to Design, CRC Press (pp. 275-304). 
Svanæs, D. \& Seland, G. (2004). Putting the users center stage: Role playing and low-fi prototyping enable end users to design mobile systems. Proceedings of the Conference on Human Factors in Computing Systems (CHI'2004), Vienna, Austria, Apr. 24-29. ACM Press, New York, NY, USA 479-486.

Taylor, J. (2004). A task-centred approach to evaluating a mobile learning environment for pedagogical soundness. In J. Attewell \& C. Savill-Smith (eds.) Proceedings of MLearn2004: Mobile Learning Anytime Everywhere, Learning and Skills Development Agency, London, UK.

Thomas J. (1985). Force field analysis: A new way to evaluate your strategy, Long Range Planning, 18(6), 54-59.

Vavoula, G.N., Sharples, M., \& Rudman, P.D. (2002). Developing the 'Future Technology Workshop’ method. In Bekker, M.M., Markopoulos, P., Kersten-Tsikalkina, M. (eds.) Proceedings of the International Workshop on Interaction Design and Children, Aug 28-29, Eindhoven, The Netherlands, 65-72.

Vavoula, G.N., Sharples, M., Cross, J., \& Baber, C. (2003). SpyCam and RoboCam: An Application of the Future Technology Workshop Method to the Design of New Technology for Children. In Proceedings of HCI International 2003, Jun 22-27, Crete, Greece. Vol. 1, pp. 1071-1075.

Vavoula, G.N., Lonsdale, P., Scanlon, E., Sharples, M., Jones, A., \& Hardy, P. (2005a). D.33.2 Report on empirical work with mobile learning \& literature on mobile learning in science. MELISSA JEIRP Project Deliverable 33.2 for Kaleidoscope European Network of Excellence.

Vavoula, G.N., Lonsdale, P., Mwanza, D., Scanlon, E., \& Hardy, P. (2005b). D.33.3 Reacting to research. MELISSA JEIRP Project Deliverable 33.3 for Kaleidoscope European Netowrk of Excellence.

Virzi, R.A. (1990). Low-fidelity prototyping. Proceedings of the Human Factors Society 33rd Annual Meeting. Santa Monica, CA., 265.

Waycott, J. (2004). The appropriation of PDAs as learning and workplace tools: an activity theory perspective. Unpublished PhD thesis, The Open University, UK. 